\title{
Pengaruh Cyberbullying Terhadap Emosi Remaja
}

\author{
Lydia Karwur Patti ${ }^{1}$, Syahrul Hidayanto ${ }^{2}$ \\ ${ }^{1}$ Sekolah Tinggi Ilmu Komunikasi InterStudi, Jakarta, Indonesia \\ 2 Sekolah Tinggi Ilmu Komunikasi InterStudi, Jakarta, Indonesia \\ *e-mail: lydia.karwur.patti@gmail.com
}

Article history: Received 17 July 2020; Accepted 30 August 2020; Available online 31 August 2020

\begin{abstract}
Abstrak
Era revolusi industri 4.0 membawa dampak pada kehidupan masyarakat sehari-hari, tak terkecuali remaja. Kehadiran media sosial dapat memberi dampak positif dan negatif bagi remaja. Tujuan dari penelitian ini adalah untuk mengetahui pengaruh cyberbullying di media sosial terhadap emosi remaja. Paradigma yang digunakan adalah positivis dengan pendekatan kuantitatif. Sumber data yang digunakan dalam penelitian ini sebanyak 50 orang. Data dikumpulkan menggunakan kuesioner dan dianalisis dengan uji validitas, reliabilitas, korelasi, regresi linear sederhana, dan hipotesis. Hasil penelitian menunjukkan bahwa terdapat pengaruh cyberbullying di media sosial Instagram terhadap emosi remaja. Hal tersebut dapat dilihat dari hasil uji hipotesis yang menunjukkan perhitungan $t$ hitung pada variabel cyberbullying di media sosial sebesar 2,423 lebih besar dari t tabel yaitu 2,011. Korelasi yang ditunjukkan antara variabel cyberbullying di media sosial dengan emosi remaja adalah korelasi yang lemah dengan nilai R Square (koefisien determinasi) sebesar 0,330. Temuan di lapangan membuktikan bahwa cyberbullying adalah bentuk perwujudan dari pelampiasan amarah yang dirasakan pelaku di dunia nyata. Selain itu, peneliti juga menemukan alasan lain, yaitu balas dendam yang tidak bisa dilakukan di dunia nyata, serta hanya sekadar mengikuti tren.
\end{abstract}

\begin{abstract}
The era of the industrial revolution 4.0 had an impact on people's daily lives, including teenagers. The presence of social media can have positive and negative impacts on teenagers. The purpose of this study was to determine the effect of cyberbullying on social media on adolescent emotions. The paradigm used is positivist with a quantitative approach. Data sources used in this study were 50 people. Data were collected using a questionnaire and analyzed with validity, reliability, correlation, simple linear regression, and hypothesis tests. The results showed that there was an influence of cyberbullying on social media Instagram on teen emotions. This can be seen from the results of the hypothesis test that shows the calculation of $t$ arithmetic on cyberbullying variables on social media by 2.423 greater than t table that is 2.011. The correlation shown between cyberbullying variables on social media with adolescent emotions is a weak correlation with the $R$ Square value (coefficient of determination) of 0.330. The findings in the field prove that cyberbullying is a form of the expression of anger that is felt by the perpetrators in the real world. In addition, researchers also found other reasons, namely revenge that can't be done in the real world, and just simply follow the trend.
\end{abstract}

Kata Kunci:

Cyberbullying; Media sosial; Emosi; Remaja

Keywords:

Cyberbullying; Social media; Emotions; Teenagers 


\section{Pendahuluan}

Masa revolusi industri 4.0, tentunya membuat teknologi yang ada semakin maju. Saat ini semua orang membutuhkan internet dalam seluruh aktivitasnya. Tentunya pengaruh media sosial saat ini di Indonesia pun terus berkembang dari waktu ke waktu. Semua orang, semua umur mempunyai media sosial dan menjadi pengguna untuk mendapat informasi dan memberi informasi (Cahyono, 2016).

Pada remaja dalam kegiatan sehari-hari memberi dampak. Media sosial bagi para remaja sangatlah penting. Perangkat yang dibuat guna mempermudah sebuah hubungan yang memiliki sifat dua arah (Paramitha \& Pratama, 2013). Pola penyebaran informasi sekarangpun berubah karena adanya media sosial yang berbasis tekonologi internet. Media sosial pun memiliki karakteristik menurut (Endarnoto, Pradipta, Nugroho, \& Purnama, 2011) yaitu capaian media sosial dari skala yang sempit hingga mendunia. Didalam pemakaian media sosial pun terdapat dampak negatif dan positif.

Dampak positif nya seperti mempermudah segala kegiatan belajar mengajar, menambah jaringan pertemanan dan juga dapat menjadi sebuah hiburan disaat penat. Tidak hanya efek positif, namun juga terdapat efek negative dalam penggunaan media sosial jika telalu sering digunakan, sebagai contoh mengganggu kegiatan belajar, banyak nya kejahatan di dunia maya seperti penipuan, dan banyak juga para pengguna media sosial bersikap tidak sopan. Salah satu dampak negatif media sosial yang diberikan kepada remaja adalah remaja menjadi tidak sopan terhadap sesamanya maupun orang yang dikenal atau tidak dikenal. Ketidaksopanan itu diwujudkan dalam bentuk cyberbullying dalam media sosial. Adapun beberapa bentuk dari cyberbullying adalah ejekan, hinaan, ancaman. Platform utama yang menjadi sarana pendukung para remaja melakukan tidakan cyberbullying ada lah media sosial.

Saat ini sudah banyak remaja yang memiliki dan menggunakan media sosial. Hampir 24 jam mereka menggunakan media sosial. Kebanyakan dari para remaja mencari informasi tentang apapun, mulai dari remaja yang mengamati kehidupan teman-temannya, membagikan video atau foto mereka, berbagi informasi apapun seputar kehidupan sehari-hari, dan tidak jarang juga remaja memberikan komentar dengan bebas tanpa memiliki rasa takut terhadap komentar bebas yang diberikan. Keberadaan media sosial mempermudah remaja untuk melakukan tindakan cyberbullying, dimana remaja dapat memposting kata-kata yang kasar dan mengunggah foto korbannya, dengan tujuan agar korbannya merasa terintimidasi dan dan tersakiti karena nama baiknya menjadi rusak. Sementara remaja pelaku cyberbullying merasa bahagia karena sudah puas karena tujuannya tercapai.

Cyberbullying di media sosial pun bermacam-macam. Jika hal ini terus dilakukan akan menimbulkan hal yang buruk, dan membuat korban cyberbullying merasa terganggu atau yang paling berbahaya adalah melakukan tindakan untuk mengakhiri hidup. Terdapat beberapa kejadian pada negara lain yang berakhir pada keputusan untuk melakukan tindakan bunuh diri karena mengalami cyberbullying. Cyberbullying tidak dapat dianggap sebagai masalah yang ringan. Siapapun yang melakukan tindakan cyberbullying akan mendapat hukuman yang sesuai Undang-Undang yang berlaku. Tujuan dari penelitian ini yaitu penulis ingin memahami lebih dalam apa yang terjadi tentang cyberbullying di kalangan remaja. Serta untuk memahami tugas orang tua, masyarakat serta pemerintah dalam masalah cyberbullying pada remaja dan tanggung jawab terhadap masalah cyberbullying ini. Agar penelitian ini dapat menghasilkan sebuah pencapaian yang baik, maka penulis ingin mengerucutkan permasalahan penelitian yang berjudul "Pengaruh Media Sosial Terhadap Perilaku Cyberbullying Pada Remaja" dan dengan cara apa media sosial mempengaruhi perilaku remaja melakukan cyberbullying serta bagaimana pengalaman remaja dan sikap mereka terhadap cyberbullying tersebut.

Perubahan yang terjadi dari seorang anak-anak menjadi seorang yang dewasa (WHO, 2017). Usia 11 - 18 tahun adalah usia perkembangan masa remaja. Kehadiran dan perkembangan internet membawa cara baru bagaimana berkomunikasi dalam kehidupan sosial (Watie, 2016). Kehadiran internet saat ini sudah merubah paradigma atau pemikiran manusia, 
bagaimana cara mereka berkomunikasi satu dengan yang lain. Kehadiran internet diyakini mendatangkan efek terhadap tingkah laku berkomunikasi sesorang (Loisa \& Setyanto, 2014).

Media sosial berkembang sangat pesat dan dengan perkembangan teknologi saat ini semakin memudahkan semua orang di dunia untuk melakukan komunikasi. Media sosial mempunyai sebuah kepasitas dalam penyaluran penjelasan guna mempengaruhi, memberi motivasi, dan melakukan tindakan yang dikehendaki oleh penyebar informasi tersebut. Sekitar 70\% dari pengguna internet diseluruh dunia, juga aktif dalam media sosial (Anwar, 2017). Namun tidak bisa dipungkiri kemajuan media sosial juga ternyata merubah beberapa perilaku manusia dalam cara berkomunikasi. Cyberbullying merupakan salah satu dari sisi gelap media sosial itu. Sisi gelap media sosial ini termasuk cyberbullying, penggunaan adiktif, trolling, perburuan penyihir online, berita palsu, dan penyalahgunaan privasi (Baccarella, Wagner, Kietzmann, \& McCarthy, 2018).

Para remaja selalu berusaha membangun citra positif didalam media sosial milik mereka. Bagi banyak orang media sosial sangat penting, terutama bagi pata remaja yang selalu menggunakan media sosial setiap saat. Oleh karena itu sangat besar kemungkinan remaja melakukan tindakan cyberbullying. Cyberbullying sering sekali terjadi dikalangan remaja, karena seorang remaja masih sangat sulit untuk memahami hal-hal atau kejadian-kejadian disekitar mereka, sehingga mereka sangat sulit menemukan solusi dari apa yang sedang dihadapi, dan akhirnya mereka memilih untuk melakukan cyberbullying. Mengutip dari jurnal (Rifauddin, 2016) yang berjudul Fenomena Cyberbullying pada Remaja

Sedangkan menurut (Rahayu, 2013) Cyberbullying adalah setiap Cyberkomunikasi atau publikasi diposting atau dikirim oleh minor online, oleh perangkat teknologi informasi yang dimaksudkan untuk menakut-nakuti, memalukan, melecehkan, menyakiti, mengatur, menyebabkan bahaya, memeras, atau sebaliknya menargetkan kecil lainnya. Cyberbullying adalah teror di dunia maya terutama pada media sosial berupa cercaan, ancaman, penghinaan, ataupun hacking (Utami, 2014). Sebagai contoh mengunggah tulisan atau gambar seseorang yang memalukan serta menyebarluaskan melalu media sosial yang ada, atau pada saat ini sedang menjadi trend membuat akun media sosial palsu untuk menghina orang lain. Teknologi telah mengubah struktur sosial kehidupan masyarakat, baik dalam cara yang baik maupun buruk (Kowalski, 2018).

Banyak anak dan remaja telah sepenuhnya merangkul dunia digital, memposting blog, mengakses situs jejaring sosial, menonton video, dan mengirim pesan instan sebagai aktivitas khas kehidupan sehari-hari mereka (Wright \& Harper, 2017). Media sosial juga telah menjadi platform utama untuk cyberbullying (Byrne, Vessey, \& Pfeifer, 2018). Remaja ini cukup terbuka dalam menunjukkan identitas mereka (Afriluyanto, 2018) Remaja cenderung melakukan cyberbullying dilandaskan rasa benci atau memiliki dendam. Pelaku cyberbullying juga melakukan hal ini untuk dilihat bahwa dirinnya memiliki kekuatan untuk melawan orang yang tidak disukai. Pada akhirnya remaja pelaku cyberbullying ini memilih media sosial sebagai sarana yang tepat untuk melampiaskan amarah atau kebenciannya. "Komentar agresif daring yang diarahkan pada teman sebaya dianggap paling negatif sedangkan komentar yang ditargetkan untuk orang acak yang hanya dikenal secara online dievaluasi paling tidak secara negatif (Whittaker \& Kowalski, 2015).

Cyberbullying telah menjadi masalah sosial yang kritis, yang sangat mengancam kesehatan fisik dan psikologis anak-anak dan remaja. (Chen, Ho, \& Lwin, 2017). Kontrol diri adalah kesanggupan meredam atau mengontrol diri nya mengatur keinginan atau kemauan dengan berbagai macam pertimbangan agar tidak ssalah dalam mengambil keputusan Hal ini yang belum dipahami sekali oleh remaja sehingga para remaja cenderung melakukan penyimpangan seperti cyberbullying. Bagi remaja cyberbullying diambil sebagai solusi dalam menyelesaikan masalah.

Untuk menghindari peningkatan cyberbullying yang sering terjadi di kalangan remaja, peran orang tua sangat dibutuhkan disini. Harus adanya pengawaasan dari orang tua kepada anak yang menggunakan media sosial. Dengan pengawasan tentunya akan mengurangi tindakan cyberbullying yang sering terjadi di kalangan remaja. Pertumbuhan teknologi memberikan efek 
berarti terhadap aktivitas masyarakat dan keluarga. Anak-anak yang lahir sesudah tahun 1980an adalah angkatan yang hidup di tengah majunya teknologi informasi (Alia \& Irwansyah, 2018).

Dapat mengurangi terjadinya cyberbullying di kalangan remaja yaitu citra diri. Citra diri pribadi dimanifestasikan dalam kejadian-kejadian terkait pribadi itu. Pendirian tentang diri sendiri, penilaian diri, dapat membangun citra diri pribadi. Kesadaran citra diri dari pandangan psikologi akan membantu citra diri positif. Citra diri positif pada gilirannya mengembangkan perangai dan interaksi positif dalam kehidupan sehari-hari (Kiling \& Kiling, 2015). Remaja adalah salah satu dari jumlah terbesar pengguna media sosial di Indonesia. Alasan awal mereka menjadi begitu aktif di media sosial adalah untuk mendapatkan perhatian, untuk mencari pendapat, dan juga untuk menampilkan citra baik diri mereka. Namun, dalam jangka panjang mereka menjadi kecanduan dalam penggunaan media sosial. Sulit bagi mereka untuk menjauh dari kegiatan yang berkaitan dengan media sosial.

Meskipun media sosial secara umum memiliki sisi positif untuk dikonsumsi, pemakaian media sosial yang berlebihan memiliki hasil negatif juga. Sebagian besar penelitian menunjukkan bahwa terlalu sering menggunakan media sosial oleh remaja memberikan konsekuensi pada peningkatan ketidaksesuaian konsep diri karena ada jarak yang besar antara pribadi nyata dan pribadi sempurna. Diri yang hadir di media sosial adalah diri ideal yang memiliki jarak yang sangat jauh dari diri yang sebenarnya. Mereka melupakan bahwa kehidupan yang nyata itu bukan pada media sosial yang mereka miliki, namun pada kehidupan mereka sehari-hari. Banyak sekali survey yang menunjukkan hasil bahwa sebagian besar remaja ingin terlihat baik di profil media sosial mereka dengan membentuk citra diri yang ideal menurut versi media sosial, meskipun itu bukan citra yang mereka miliki dalam diri yang sebenarnya. Dengan mengurangi konsumsi media sosial, remaja akan lebih produktif dan mengembangkan konsep diri positif mereka dalam kehidupan nyata mereka (Felita et al., 2016). Berdasarkan latar belakang tersebut, tujuan dari penelitian ini adalah untuk mengetahui pengaruh cyberbullying di media sosial terhadap emosi remaja.

\section{Metode}

Studi ini memanfaatkan metode kuantitatif. Metode kuantitatif adalah metode penelitian yang dilandaskan paham positivisme, guna menggali populasi. Sedangkan (Caldas, 2003) memaparkan penelitian kuantitatif merupakan studi pendidikan yang mana peneliti mememastikan studi yang dikaji.

Survei sebagai cara mengumpulkan hasil studi. Kuisioner menjadi pilihan dalam studi ini. Kuisoner dibagikan pada 50 responden. Dan peneliti akan menyebarkan kuisioner secara tidak langsung melalui google form. "Variabel penelitian adalah suatu atribut atau sifat nilai dari orang objek atau kegiatan yang mempunya variasi tertentu yang ditetapkan oleh peneliti untuk dipelajari sehingga diperoleh informasi tentang hal tersebut, kemudian ditarik kesimpulannya" (Sugiyono, 2008). Variabel dalam penelitian dibagi menjadi dua variabel yaitu, variabel bebas atau independent variabel $(\mathrm{x})$ adalah cyberbullying dan variabel terikat atau dependent variabel (y) adalah emosi remaja.

Menurut (Barsbold, Osmólska, Watabe, Currie, \& Tsogtbaatar, 2000) populasi yaitu keutuhan sasaran studi berbentuk mahluk hidup, tumbuhan sehingga target memanifestasikan sumber petunjuk studi. Populasi adalah keseluruhan hasil yang menjadi pusat perhatian seorang peneliti dalam ruang lingkup dan waktu yang telah ditentukan" populasi berkaitan dengan datadata, jika seorang manusia memberikan suatu hasil, maka perhitungan atau besarnya populasi akan sama besarnya dengan makhluk. (Margono, 2010).

Selanjutnya adalah analisis penelitian data kuantitatif dalam studi ini memanfaatkan perangkat SPSS untuk mengadaptasi bahan yang sudah terkumpul. Karakteristik demografis dihitung dengan frekuensi, sedangkan untuk uji pertanyaan survei menggunakan validitas dan relabilitas menggunakan rumus SPSS, dan kemudian menganalisis dengan statistik. Menurut (Sugiyono, 2008) validitas serta realibilitas diuji sebelum instrumen dimanfaatkan. 


\section{Hasil dan Pembahasan}

Pengambilan keputusan uji ini dilandaskan dengan membandingkan nilai $r$ hitung dengan $r$ tabel. Jumlah responden dalam penelitian ini adalah 50 orang, maka nilai $r$ tabelnya adalah 0,279. Hasil uji validitas seperti terlihat pada Tabel 1.

Tabel 1.

Uji Validasi

\begin{tabular}{llll}
\hline Item Pertanyaan & r hitung & r table & Kesimpulan \\
\hline X1 & 0,373 & 0,279 & Valid \\
\hline X3 & 0,598 & 0,279 & Valid \\
\hline X4 & 0,660 & 0,279 & Valid \\
\hline X5 & 0,379 & 0,279 & Valid \\
\hline X6 & 0,681 & 0,279 & Valid \\
\hline X7 & 0,671 & 0,279 & Valid \\
\hline X9 & 0,610 & 0,279 & Valid \\
\hline X10 & 0,610 & 0,279 & Valid \\
\hline Y1 & 0,358 & 0,279 & Valid \\
\hline Y2 & 0,286 & 0,279 & Valid \\
\hline Y3 & 0,555 & 0,279 & Valid \\
\hline Y4 & 0,595 & 0,279 & Valid \\
\hline Y5 & 0,586 & 0,279 & Valid \\
\hline Y6 & 0,435 & 0,279 & Valid \\
\hline Y7 & 0,541 & 0,279 & Valid \\
\hline Y8 & 0,421 & 0,279 & Valid \\
\hline Y9 & 0,394 & 0,279 & Valid \\
\hline Y10 & 0,328 & 0,279 & Valid \\
\hline & 0,390 & 0,279 & Valid \\
\hline
\end{tabular}

Berdasarkan uji validitas di atas, tidak ditemukan ketidakvalidan dalam variabel $\mathrm{X}$ maupun variabel Y. Maka dari itu, semua item kuesioner dapat dikatakan valid atau sudah dapat mengukur apa yang telah diukur karena memiliki r hitung lebih besar dari 0,279.

\section{Uji Reliabilitas}

Hasil uji reliabilitas adalah sebagai berikut.

Tabel 2.

Reliability Statistics

\begin{tabular}{c|c} 
Cronbach's Alpha & N of Items \\
\hline .829 & 19 \\
\hline
\end{tabular}

Tabel 2 menujukkan hasil uji reliabilitas dengan teknik cronbach's alpha adalah 0,829. Kuesioner dapat dikatakan reliabel apabila nilainya > 0,60. Maka, dapat dikatakan bahwa kuesioner ini reliabel, atau dengan kata lain jika data kuesioner tersebut dilakukan pengukuran ulang, maka data tersebut dapat dipercaya.

\section{Demografi}

Dalam penelitian kali ini, peneliti mengambil sampel sebanyak 50 orang, dengan karakterisktik responden seperti berikut. 


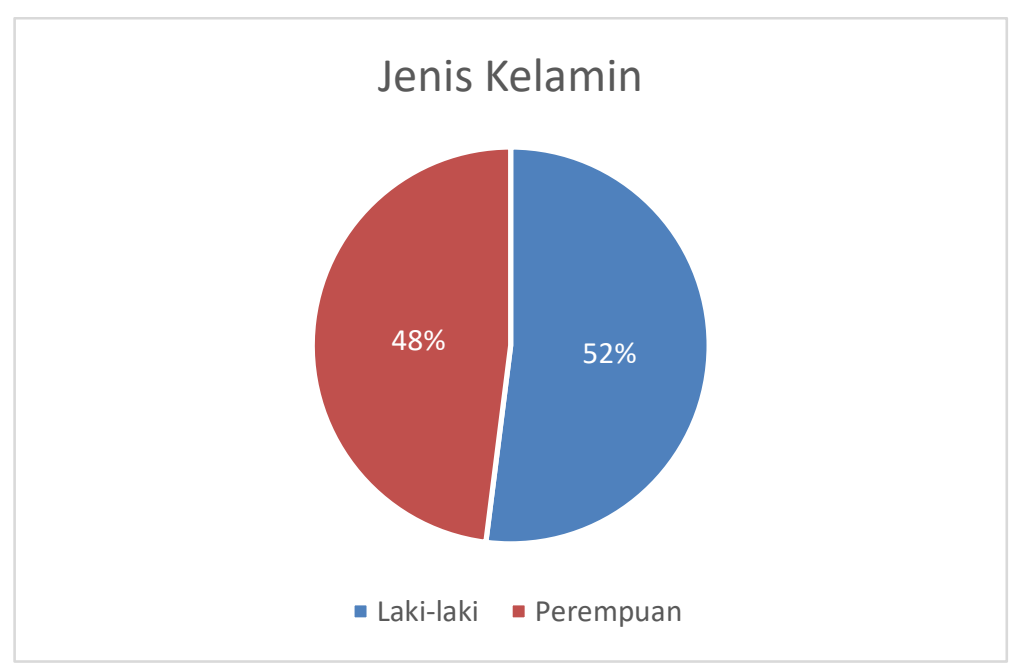

Gambar 1. Karakteristik Jenis Kelamin

Jenis kelamin responden didominasi oleh jenis kelamin laki-laki dengan persentase $52 \%$.

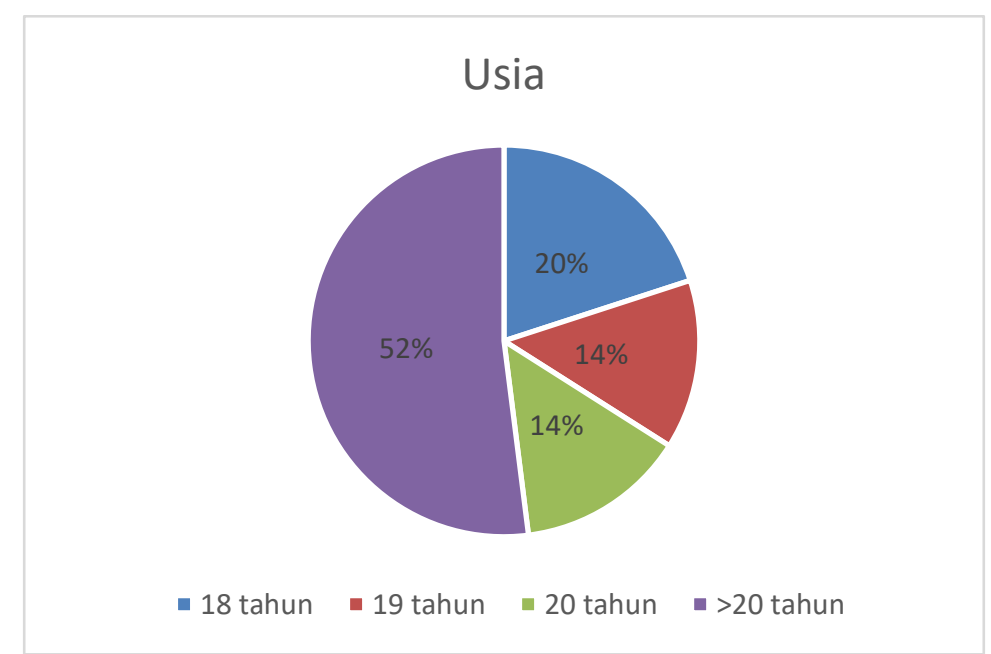

Gambar 2. Karakteristik Usia

Usia responden didominasi oleh usia lebih dari 20 tahun dengan persentase 52\%.

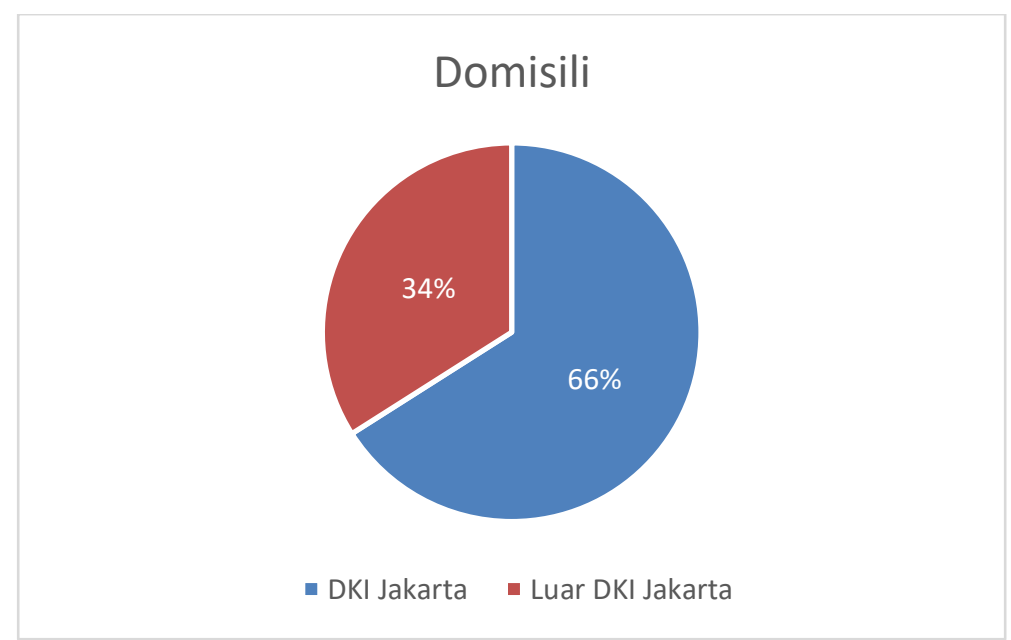

Gambar 3. Karakteristik Domisili

Domisili responden didominasi oleh domisili DKI Jakarta dengen persentase sebesar 66\%. 


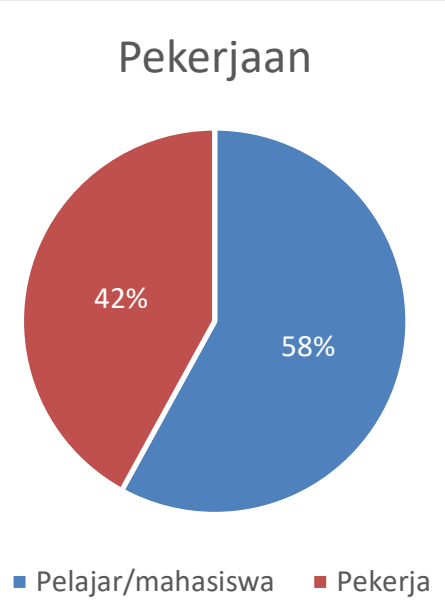

Gambar 4. Karakteristik Pekerjaan

Pekerjaan responden didominasi oleh para pelajar atau mahasiswa dengan persentase sebesar $58 \%$.

\section{Uji Korelasi}

Hasil uji korelasi dalam penelitian ini adalah sebagai berikut:

Tabel 3.

Correlations

\begin{tabular}{llll|l} 
& & $\begin{array}{l}\text { Cyberbullying } \\
\text { Instagram }\end{array}$ & di & Emosi Remaja \\
\hline Cyberbullying di Instagram & Pearson Correlation & 1 & $.330^{*}$ \\
\cline { 2 - 4 } & Sig. (2-tailed) & & .019 \\
\cline { 2 - 4 } Emosi Remaja & $\mathrm{N}$ & 50 & 50 \\
\hline & Pearson Correlation & $.330^{*}$ & 1 \\
\cline { 2 - 4 } & Sig. (2-tailed) & .019 & 50 \\
\cline { 2 - 4 } & $\mathrm{N}$ & 50 & \\
\hline
\end{tabular}

* Correlation is significant at the 0.05 level (2-tailed).

Tabel di atas menunjukkan nilai sig. (2-tailed) adalah 0,019. Jika nilai si. (2-tailed) $<0,05$ maka terdapat hubungan antara variabel X dengan variabel Y. Oleh karena itu, dapat dikatakan bahwa terdapat hubungan antara cyberbullying di Instagram (X) dengan emosi remaja (Y).

Berdasarkan Tabel 3, diketahui nilai pearson correlation adalah 0,330 yang berarti bahwa terdapat korelasi yang lemah antara cyberbullying di Instagram (X) dengan emosi remaja (Y).

\section{Uji Regresi Linear Sederhana}

Tabel 4.

Model Summary

\begin{tabular}{ll|l|l|l} 
& & \multicolumn{2}{|c}{} & $\begin{array}{l}\text { Std. Error of the } \\
\text { Estimate }\end{array}$ \\
\hline 1 & $\mathrm{R}$ & R Square & Adjusted R Square & 3.83896 \\
\hline
\end{tabular}

a. Predictors: (Constant), Cyberbullying di Instagram

Nilai R Square (koefisien determinasi) sebesar 0,109 yang artinya pengaruh cyberbullying di Instagram (X) terhadap emosi remaja (Y) sebesar 10,9\%. Kemudian 89,1\% dipengaruhi oleh faktor lain. 
Tabel 5.

Coefficients ${ }^{\mathrm{a}}$

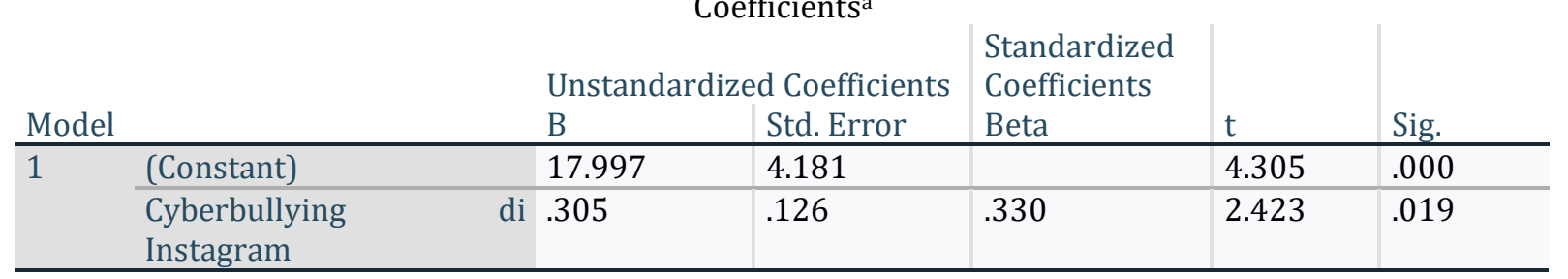

a. Dependent Variable: Emosi Remaja

Diketahui nilai constant sebesar 17,997 dan angka koefisien regresi sebesar 0,305 sehingga diperoleh persamaan regresi sebagai berikut:

$$
\begin{gathered}
Y=a+b X \\
Y=17,997+0,305 X
\end{gathered}
$$

\section{Uji Hipotesis}

\section{Hipotesis penelitian:}

Ho = Tidak ada pengaruh cyberbullying di media sosial Instagram (X) terhadap emosi remaja (Y) $\mathrm{Ha}=$ Ada pengaruh cyberbullying di media sosial Instagram (X) terhadap emosi remaja (Y)

Pengambilan keputusan dalam uji hipotesis ini dilakukan dengan mengadakan perbandingan $t$ tabel dengan $t$ hitung. Untuk mengetahui nilai $t$ tabel, perlu diketahui derajat kebebasan. Adapun derajat kebebasan dalam penelitian ini diperoleh dari rumus $n-k$, sehingga nilainya adalah 48. Dengan demikian, nilai t tabel adalah 2,011. Sementara itu, nilai t hitung dapat diketahui melalui tabel coefficients, yaitu 2,423.

Berdasarkan nilai $t$ tabel dengan $t$ hitung, sehingga diketahui Ha diterima dan Ho ditolak mengartikan terdapat pengaruh cyberbullying di media sosial Instagram (X) terhadap emosi remaja (Y). hal ini dikarenakan nilai t hitung > t tabel.

\section{Pengaruh Cyberbullying terhadap Emosi Remaja}

Tidak ada alasan yang tepat mengapa cyberbullying terjadi. Kebebasan berpendapat pada media sosial terkadang disalahgunakan bagi beberapa orang. Ketika mereka memiliki sebuah masalah di dunia nyata maka hal tersebut akan mereka lampiaskan di dunia nyata. Itulah salah satu hal yang menyebabkan terjadinya cyberbullying di media sosial. Penelitian ini juga menemukan hasil yang sejalan dengan penelitian Baccarella et.al. (2018) terkait beberapa alasan lain penyebab terjadinya cyberbullying, yaitu balas dendam yang tidak bisa dilakukan di dunia nyata, trend atau hanya ikut-ikutan.

Cyberbullying sering terjadi di media sosial dapat dipastikan bahwa media sosial dengan mudah dan cepat menyebarkan segala sesuatu. Kecepatan penyampaian pesan sebagai dasar mengapa media sosial sering digunakan dibandikan dengan platform lain. Dan dapat dipastikan juga bahwa korban-korban cyberbullying pasti memiliki akun media sosial. Kecenderungan seseorang menggunakan media sosial lah juga yang menjadi dasar mengapa media sosial selalu menjadi sarana dilakukannya cyberbullying, dibandikan dengan platform lain (Loisa and Setyanto 2014).

Penelitian ini menemukan temuan yang menarik, yaitu cyberbullying yang terjadi saat ini banyak didominasi oleh kalangan remaja. Beberapa diantara mereka menjadi pelaku tapi tidak banyak juga dari mereka menjadi korban. Pengaruh cyberbullying yang nyata terlihat pada remaja adalah hilangnya konsep diri. Para remaja tidak menjadi dirinya sendiri pada media sosial, dan cenderung melakukan hal-hal yang menyimpang ketika mereka mengalami hal yang tidak diinginkan. Remaja cenderung bereaksi negatif seperti membully orang-orang yang tidak mereka sukai. Itulah pengaruh cyberbullying ketika mereka menjadi pelaku, namun ketika mereka berada diposisi sebagai korban cyberbullying, pengaruh yang nyata adalah mereka cenderung tertutup, tidak membuka diri, dan tidak sedikit menyimpan dendam. Lebih nyata dan yang sangat terlihat adalah mereka sering menutupi kesedihan secara emosional. 


\section{Simpulan dan Saran}

Berlandaskan hasil studi yang sudah dilaksanakan pada Hasil Olah Data serta pembahasan maka ditarik kesimpulan bahwa terdapat hubungan atau korelasi antara cyberbullying di Instagram dengan emosi remaja. Hal ini dibuktikan berdasarkan hasil uji korelasi yaitu nilai sig. (2-tailed) adalah 0,019. Jika nilai si. (2-tailed) <0,05 maka terdapat hubungan antara variabel X dengan variabel Y dan nilai pearson correlation adalah 0,330 yang berarti bahwa terdapat korelasi yang lemah antara cyberbullying di Instagram dengan emosi remaja. Pengaruh cyberbullying terhadap emosi remaja hanya mempunyai pengaruh $10,9 \%$ hal ini ditunjukan pada Uji Nilai R Square (koefisien determinasi) sebesar 0,109 yang artinya pengaruh cyberbullying di Instagram terhadap emosi remaja sebesar 10,9\%. Kemudian 89,1\% dipengaruhi oleh factor lain. Berdasarkan nilai $t$ tabel dengan $t$ hitung, maka dapat diketahui bahwa Ha diterima dan Ho ditolak yang artinya ada pengaruh cyberbullying di media sosial Instagram terhadap emosi remaja.

\section{Daftar Pustaka}

Afriluyanto, T. R. (2018). Fenomena Remaja Menggunakan Media Sosial dalam Membentuk Identitas. KOMUNIKA: Jurnal Dakwah Dan Komunikasi. https://doi.org/10.24090/komunika.v11i2.1365

Alia, T., \& Irwansyah. (2018). Pendampingan Orang Tua pada Anak Usia Dini dalam Penggunaan Teknologi Digital. A Journal of Language, Literature, Culture and Education. https://doi.org/10.19166/pji.v14i1.639

Anwar, F. (2017). Perubahan dan Permasalahan Media Sosial. Jurnal Muara Ilmu Sosial, Humaniora, Dan Seni. https://doi.org/10.24912/jmishumsen.v1i1.343

Baccarella, C. V., Wagner, T. F., Kietzmann, J. H., \& McCarthy, I. P. (2018). Social media? It's serious! Understanding the dark side of social media. European Management Journal. https://doi.org/10.1016/j.emj.2018.07.002

Barsbold, R., Osmólska, H., Watabe, M., Currie, P. J., \& Tsogtbaatar, K. (2000). A new oviraptorosaur (Dinosauria, Theropoda) from Mongolia: The first dinosaur with a pygostyle. Acta Palaeontologica Polonica.

Byrne, E., Vessey, J. A., \& Pfeifer, L. (2018). Cyberbullying and Social Media: Information and Interventions for School Nurses Working With Victims, Students, and Families. Journal of School Nursing. https://doi.org/10.1177/1059840517740191

Cahyono, A. S. (2016). Pengaruh media sosial terhadap perubahan sosial masyarakat di Indonesia. Jurnal Ilmu Sosial \& Ilmu Politik Diterbitkan Oleh Fakultas Ilmu Sosial \& Politik, Universitas Tulungagung.

Caldas, M. (2003). Research design: qualitative, quantitative, and mixed methods approaches. Revista de Administração Contemporânea, 7, 223. https://doi.org/10.1590/S141565552003000100015

Chen, L., Ho, S. S., \& Lwin, M. O. (2017). A meta-analysis of factors predicting cyberbullying perpetration and victimization: From the social cognitive and media effects approach. New Media and Society. https://doi.org/10.1177/1461444816634037

Endarnoto, S. K., Pradipta, S., Nugroho, A. S., \& Purnama, J. (2011). Traffic condition information extraction \& visualization from social media twitter for android mobile application. Proceedings of the 2011 International Conference on Electrical Engineering and Informatics, ICEEI 2011. https://doi.org/10.1109/ICEEI.2011.6021743

Felita, P., Siahaja, C., Wijaya, V., Melisa, G., Chandra, M., \& Dahesihsari, R. (2016). Pemakaian Media Sosial Dan Self Concept Pada Remaja. Jurnal Ilmiah Psikologi, 5(1), 30-41.

Kiling, B. N., \& Kiling, I. Y. (2015). Tinjauan Konsep Diri Dan Dimensinya Pada Anak Dalam Masa Kanak-Kanak Akhir. Jurnal Psikologi Pendidikan Dan Konseling: Jurnal Kajian Psikologi Pendidikan Dan Bimbingan Konseling. https://doi.org/10.26858/jpkk.v1i2.1811

Kowalski, R. (2018). Cyberbullying. In The Routledge International Handbook of Human Aggression: Current Issues and Perspectives. https://doi.org/10.4324/9781315618777 
Loisa, R., \& Setyanto, Y. (2014). Penyingkapan Diri Melalui Internet Di Kalangan Remaja (Studi Komunikasi Antar Pribadi). Jurnal Komunikasi Untar.

Margono. (2010). Doc 21. In Metodologi Penelitian Pendidikan.

Paramitha, S., \& Pratama, A. (2013). Shale gas potential in bintuni basin - New insights to the future hydrocarbon resources in Indonesia. 75th European Association of Geoscientists and Engineers Conference and Exhibition 2013 Incorporating SPE EUROPEC 2013: Changing Frontiers. https://doi.org/10.3997/2214-4609.20131120

Rahayu, F. S. (2013). Cyberbullying Sebagai Dampak Negatif Penggunaan Teknologi Informasi. Jurnal Sistem Informasi. https://doi.org/10.21609/jsi.v8i1.321.

Rifauddin, M. (2016). Pengelolaan Arsip Elektronik Berbasis Teknologi. Khizanah Al- Hikmah Jurnal Ilmu Perpustakaan, Informasi, Dan Kearsipan.

Sugiyono. (2008). Metode Penelitian Kuatintatif, Kualitatif dan R\&D 2008. In Alfabeta. https://doi.org/2008.

Utami, Y. C. (2014). Cyberbullying di Kalangan Remaja. Universitas Airlangga.

Watie, E. D. S. (2016). Komunikasi dan Media Sosial (Communications and Social Media). Jurnal The Messenger, 3(2), 69. https://doi.org/10.26623/themessenger.v3i2.270.

Whittaker, E., \& Kowalski, R. M. (2015). Cyberbullying Via Social Media. Journal of School Violence. https://doi.org/10.1080/15388220.2014.949377

WHO. (2017). Definisi Remaja.

Wright, M. F., \& Harper, B. D. (2017). Cyberbullying. In Advances in Sociology Research. https://doi.org/10.4018/jte.2010070103. 